\title{
Social Determinants of Quality Health Care for a Diverse Society
}

\author{
Nancy Norman-Marzella, RN, MSN, NP, CNE ${ }^{1,2}$ \\ 1. Associate Professor of Nursing, Lincoln University of Pennsylvania, 1570 Baltimore Pike, Lincoln Univeristy, \\ PA 19352 \\ 2. Graduate Student Walden University, Doctor of Nursing Practice, 100 S Washington Ave \#900, Minneapolis,
} MN 55401

\begin{abstract}
Increasing the amount of health care workers from diverse constituents can inform health care professions about ways to improve care for underserved populations. The U. S. Department of Health and Human Services (HHS, 2014) Healthy People 2020 goals related to health equity include: 1) Eliminating disparities, 2) Creating social and physical environments that promote good health, quality of life, healthy development, and 3) Promote healthy behaviors across the life span [1]. Strategies to increase the number of minorities represented in the nursing workforce include innovative academic mentoring programs at the baccalaureate level that cultivate student-to-student and faculty-to-student training cohorts (Metcalfe, 2015). [2]. Despite these efforts, disparities continue in the number of students and available minority faculty prepared at the doctoral level. According to the National Council of State Boards of Nursing (NCSB, 2013) annual survey, 12.3 percent of full-time faculty were from minority backgrounds and only 5.4 percent were males [3].
\end{abstract}

Keywords: Health Care Quality, Diversity, Social Determinants of Health, Health Care Workers, Nursing Workforce, Nursing Education

\section{Introduction}

Variations in medical coverage frameworks influence individuals of all ages, races, ethnicities, and salary levels; those with the least salaries face the most danger of being uninsured (The Commonwealth Fund, 2015) [4]. Being uninsured influences individuals' ability to receive medical care and impacts financial resources. The barriers confronting uninsured individuals means they are more likely to suffer averse health due to the lack of preventive care, and hospitalized for conditions that could have been averted. The disadvantaged are more likely to die premature deaths due to lack of adequate care. The financial consequences of balancing basic needs with health-related cost considerations mean that medical attention can lead to an enormous debt that families are not able to pay (Majerol, Newkirk \& Garfield, 2015) [5].

The U. S. Department of Health and Human Services (HHS, 2014) Healthy People 2020 goals related to health equity include: 1) Eliminating disparities, 2) Creating social and physical environments that promote good health, quality of life, healthy development, and 3) Promote healthy behaviors across the life span [6]. The American Association of Colleges of Nursing (2015) state there is a consensus by all stakeholders, for example, nursing organizations (state and federal), and the American Hospital Associations, that recruiting underrepresented groups into nursing and the health care workforce is a priority [7].

Increasing the amount of health care workers from diverse constituents can inform the profession about ways to improve care for underserved populations. Cultural competence goes beyond receiving care from a provider with the same ethnic, cultural, and demographic characteristic of the patient. Culturally competent care reduces the harm caused by errors and improves patient satisfaction because its helps to ensure an understanding of the communication between the provider and the patient (Stiefel \& Nolan, 2012) [8]. The current nursing workforce does not represent the population it serves thus affecting the quality of health care for disadvantaged patients. Therefore, a more diverse workforce in the U. S. is imperative to improve the quality of health care. 


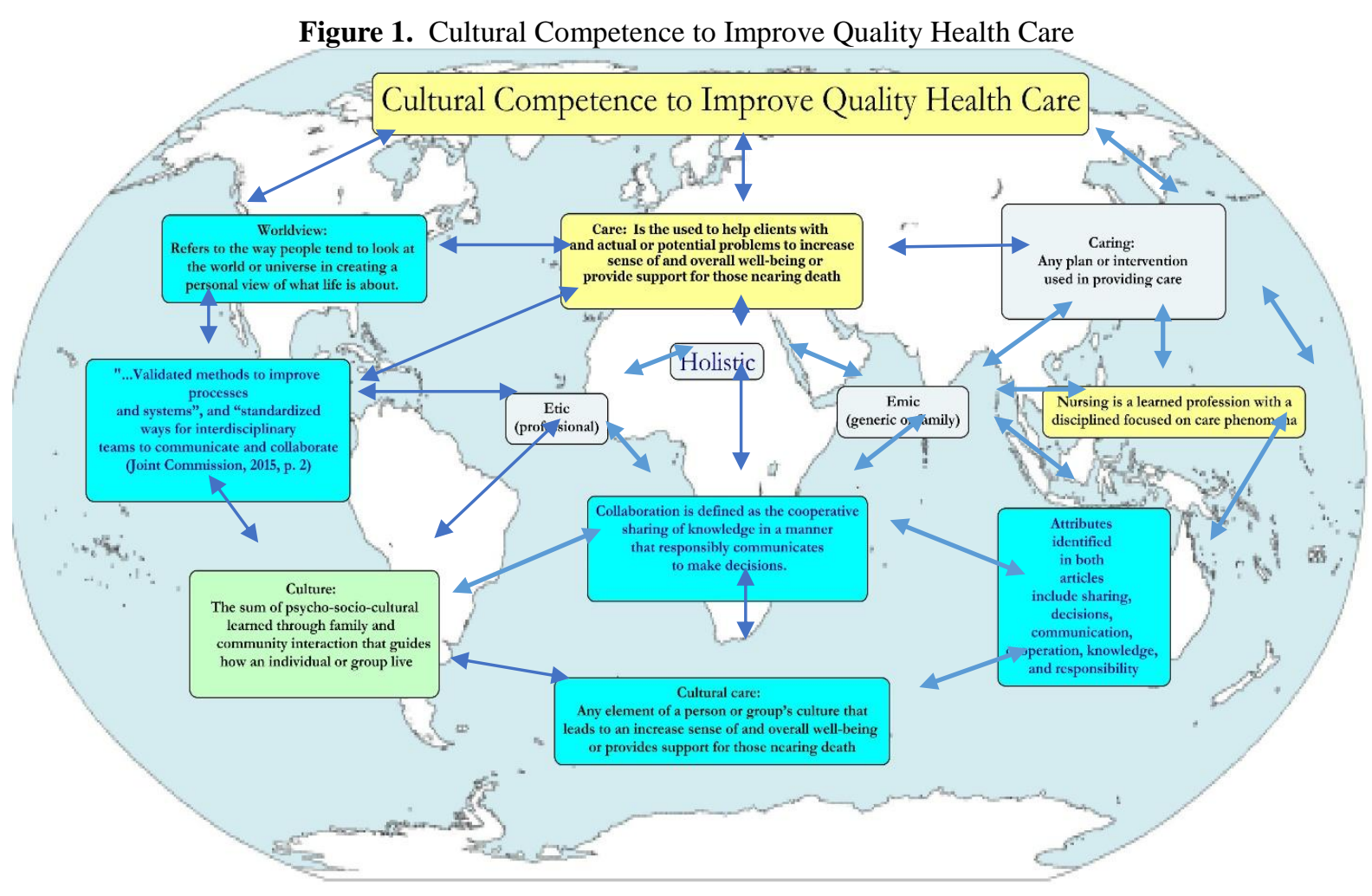

II. Current Characteristics

Men make up 14.1 percent of the nursing workforce which is an increase but does not reflect the number of male nurses needed given the population served by nurses. Eighty-three percent of registered nurses are white; 6 percent are African American; 6 percent or Asian; 3 percent are Hispanic; 1 percent are American Indian/Alaskan Native; 1 percent are Native Hawaiian/ Pacific Islander, and 1 percent represents other (National Council of State Boards of Nursing [NCSBN], 2015) [9]. Minorities more than whites pursue a baccalaureate nursing education and advanced preparation in the field of nursing (NCSBN, 2015) [9].

The Institute of Medicine (IOM) report The Future of Nursing recommends that nurses should achieve higher levels of education and training through an improved education system that promotes seamless academic progression (IOM, 2010, p. 2) [10]. Also, a more diverse workforce is imperative to provide quality patient care related to gender and race/ethnicity to represent the patient population it serves (IOM, 2010) [10]. Recommendations indicate there are a need for more gender and race/ethnically diverse nurses to achieve this goal. The current policy is a redistributive, governmental policy at the level of implementation, aimed at allocating resources for a more diverse health care workforce to improve the quality of care (Bodenheimer \& Grumbach, 2012) [11].

\section{Analysis Framework}

Social. The United States Census Bureau (2012) reports $37 \%$ of the population are of minority background and by 2043, the current minority groups will comprise the majority population. High-quality care is a social mandate and is consistent with the idea of health equity. Research and health policies related to social determinants of health indicate there is a gap in health care quality for disadvantaged populations in the U.S [12].

Ethical. The American Nurses Association (ANA, 2015) Code of Ethics specifically Provisions 6-9 articulate the values of social justice in nursing and health policy. For example, Provision 8 states; "The nurse collaborates with other health professionals and the public to protect human rights, promote health diplomacy, and reduce health disparities" (ANA, 2015, p. 31) [13]. The nursing code of ethics unifies the profession in national and global health policies related to health as a universal right.

Legal. The 1964 Civil Rights Act prohibits discrimination in programs receiving federal assistance [14]. In 1965, Medicare and Medicaid received approval for federal funding as programs that reimburse hospitals and health care providers for services. Therefore, discrimination in the care reimbursed by Medicare and Medicaid isprohibited because these programs receive federal funding [15]. In 1989, the Nursing Workforce Diversity (NWD) program was mandated through the Title VIII Public Health Service Act to increase the number of opportunities in nursing education for underrepresented and disadvantaged individuals (Williams 
\& Hansen, 2014) [16]. The mandate included funding, mentoring, and social support. Adopting a social determinants framework, the Nursing Division (ND) of the Health Resources and Services Administration's (HRSA) established evidence-based assumptions to improve health outcomes by diversifying the nursing workforce including:

1) Health professionals who are from racial/ethnic minority groups and come from socioeconomically disadvantaged backgrounds are more likely to serve in resource-poor and rural communities, where racial/ethnic minority groups and the poor are overrepresented.

2) Racial/ethnic and language concordance will improve patient-provider communication, tolerance, trust, and decision-making, thereby increasing access to, and quality of, the interaction that would result in improved health outcomes.(Williams \& Hansen, 2014) [16]

Historical. In 2004, findings from the Sullivan Commission on Diversity determined the impact on the social determinants of health is dependent upon the quality of interactions between patients with their team of health care workers. To ameliorate inequities, the Commission concluded that stakeholders would need to address the lack of diversity in the health care workforce, and to achieve greater diversity, the Commission made recommendations with the following assertions:

1) To increase diversity in the health professions, the culture of health professions schools must change;

2) New and nontraditional paths to the health professions should be explored;

3) Commitments must be at the highest levels of our government and in the private sector. (Sullivan, 2004, p. v) [17]

Financial /economic. The Patient Protection and Affordable Care Act (PPACA, 2010) increased the authority of the NWD to include funding for nurses with diplomas and associate degrees to pursue a baccalaureate degree in nursing (PPACA, 2010) [18]. Approximately $\$ 160$ million has been awarded in grants to U. S. schools of nursing. Creating equity in health care necessitates redistribution of health care dollars. Redistribution of health care funding creates tension for insurers and health care markets.

\section{Conclusion and Recommendations}

Congruency in health equity policy and current initiatives in Primary Care, access to care, and affordability is a strategy to support policies that advocate for equity and improve social determinants of health. The American Association of Colleges of Nursing (2014) endorsed the evidence-based recommendations from the IOM (2010) report, The Future of Nursing that established a goal to increase the number of nurses practicing at the baccalaureate level to 80 percent by 2020 [11]. Recommendations based upon changes in the health care delivery systems, disparity in the nursing workforce included: 1) The need for nurses to be culturally competent;2) To practice with a broader scope; and3) To understand the socio-political-economics that influence patient care and the health care system (IOM, 2010) [11].

There is progress in the implementation of health equity policies, but it has taken a long time (almost three decades). For example, the NWD mandate occurred in 1989, the Sullivan Commission findings were in 2004, and the IOM report on The Future of Nursing was 2010. With partial changes, more underserved populations have health care access and the quality of attention that has improved in response to their needs. Nurse leaders participate in inter-professional collaboration to continue moving the policy forward although gaps in care continue to occur (American Nurses Association, 2010) [14]. Acute episodic care remains at the forefront of healthcare delivery. However, primary prevention occurs among inter-professional teams although the teams do not adequately represent the diversity of their constituents. Health care costs remain disproportionate to services available, and insurance carriers remain the main beneficiaries. There is discussion on the social determinants of health, but the impact of determinants in the role of health equity continues to be explored. Emerging care in primary prevention as a key factor in assuring a healthier patient population becomes the main focus of health care delivery. Hospitals and insurance companies begin working with patient advocacy groups and government agencies to align service markets with needs.

Completely implementing health equity policy means there is opportunity for full representation of underserved populations in the health care workforce to provide care for a diverse group of patients. Health care equity is achieved, and all segments of the patient population have access to the care and coverage to meet their needs. The entire patient population receives quality care across the continuum of service markets and delivery systems (Joint Center for Political and Economic Studies, 2010) [19]. There is less need for acute episodic care as health concerns are addressed through early intervention resulting in lower mortality and morbidity of the entire patient population. The characteristics and demographics of the workforce are consistent with the patient population. Nurse leaders are fully vested and equal partners with inter-professional teams in the policy, actively participating in advocacy programs to ensure the representation of all constituents. There is an established definition of social determinants of health that continues to evolve with evidence-based research on the needs of 
specific populations.

The Institute for Healthcare Improvement (IHI) states that quality health care includes improving the care and experience of patients while controlling cost. The Triple Aim calls for a commitment from organizations providing health care services to develop partnerships with patients, restructure the primary care system, manage health of the population, be fiscally responsible, and integrate large health care systems (Berwick, Nolan \& Whittington, 2008) [20]. The Triple Aim is congruent with the IOM report on The Future of Nursing identifying diversity as one of the major quality determinants of patient care, satisfaction, and cost. The implications for research include the use of Middle-range theories to test the effectiveness of models for health care quality and equity through workforce diversity. A broadened research agenda to increase the amount of research focus on health disparities and social determinants of health will promote a greater understanding of the phenomenon that influence health and improves outcomes (Williams \& Hansen, 2014) [17].

Leveraging support from national organizations such as the ANA, the American Medical Association, the National Academies, the Institute for Healthcare Improvement are some examples of organizations that currently support health equity policies. Medical coverage is a concern that draws national attention. Identifying the congruency in health equity policy and current initiatives in Primary Care, access to care, and affordability is a strategy to support policies that advocate for equity and improve social determinants of health.

This work received no specific grant from any funding agency in the public, commercial, or not-for-profit sectors.

\section{Acknowledgement}

The author wishes to acknowledge the Dr. Aboul-Enein for his mentorship, Frank Webster for his exemplary leadership and dedication to fair and equitable treatment of all people, Julia Gould for her contributions to professional nursing, andDr.Madeline Leininger, anthropologist and founder of transcultural nursing.

\section{References}

[1] U.S. Department of Health and Human Services. Office of Disease Prevention and Health Promotion. (2014). Healthy People 2020 leading health indicators: Progress report.Washington, DC. Retrieved from https://www.healthypeople.gov/sites/default/files/LHIProgressReport-ExecSum 0.pdf

[2] Metcalfe, S. E. (2015). Creative and innovative mentoring program for improving diversestudents in education. International Archives of Nursing and Health Care, 1(2), 1-4.Retrievedfrom http://clinmedjournals.org/articles/ianhc/international-archives-ofnursing-and-health-care-ianhc-1-015.pdf

[3] National Council of State Boards of Nursing. (2013). The National Council of State Boards of Nursing and The Forum of State Nursing Workforce Centers 2013 National Workforce Survey of RNs. Journal of Nursing Regulation, 4(Suppl.), S1-S72.

[4] The Commonwealth Fund. (2015, March). Closing the gap: Past performance ofhealth insurance in reducing racial and ethnic disparities in access to care could be an indication of future results. Retrieved from http://www.commonwealthfund.org/ /media/files/publications/issue-

brief/2015/mar/1805_hayes_closing_the_gap_reducing_access_disparities_ib_v2.pdf

[5] Majerol, M., Newkirk, V. \& Garfield, R. (2015, November). The uninsured: A primer - key facts about health insurance and the uninsured in the era of health reform. Retrieved from http://kff.org/report-section/the-uninsured-a-primer-key-facts-about-healthinsurance-and-the-uninsured-in-the-era-of-health-reform-what-was-happening-to-insurance-coverage- leading-up-to-the-aca/

[6] U.S. Department of Health and Human Services. Office of Disease Prevention and Health Promotion. (2014). Healthy People 2020 leading health indicators: Progress report. Washington, DC. Retrieved from https://www.healthypeople.gov/sites/default/files/LHIProgressReport-ExecSum_0.pdf.

[7] American Association of Colleges of Nursing. (2015, March). Enhancing diversity in the workforce. Retrieved from http://www.aacn.nche.edu/media-relations/fact-sheets/enhancing-diversity

[8] Stiefel, M. \& Nolan, K. (2012). A guide to measuring the triple aim: Population health,experience of care, and per capita cost. IHI Innovation Series white paper. Cambridge, Massachusetts: Institute for Healthcare Improvement. Retrieved from IHI.org

[9] National Council of State Boards of Nursing. (2015, September). 2015 National nursing workforce study. Retrieved from https://www.ncsbn.org/workforce.htm

[10] Institute of Medicine. (2010). The future of nursing: Leading change, advancing health: Report brief. Retrieved from http://www.iom.edu/ /media/Files/Report Files/2010/The-Future-of-Nursing/Future of Nursing 2010 Report Brief.pdf

[11] Bodenheimer, T., \& Grumbach, K. (2012). Understanding health policy: A clinical approach (6th ed.). New York, NY: McGraw-Hill.

[12] U. S. Census Bureau. (2012, December). U.S. Census Bureau projections show a slower growing, older, more diverse nation a half century from now. Retrieved from http://www.census.gov/newsroom/releases/archives/population/cb12-243.html

[13] American Nurses Association. (2015). Code of ethics for nurses with interpretive statements 2015. Silver Spring, MD: American Nurses Association.

[14] Civil Rights Act of 1964, Pub.L. 88-352, 78 Stat. 241 (1964)

[15] Social Security Amendments of 1965, Pub.L. 89-97, 79 Stat. 286, enacted July 30, 1965.

[16] Williams, S., Hansen, K. (2014, January/February). Nursing in 3D: Workforce diversity, health disparities, and social determinants of health, Public Health Reports, 29(8). Retrieved from

http://www.publichealthreports.org/issuecontents.cfm? Volume $=129 \&$ Issue $=8$

[17] Sullivan, L. W. (2004). Missing persons: Minorities in the health professions, a report of theSullivan Commission on diversity in the healthcare workforce. Other. UNSPECIFIED.

[18] Retrieved from http://www.aacn.nche.edu/media-relations/SullivanReport.pdf 
[19] Patient Protection and Affordable Care Act. (2010). Title VIII, § 821 of the Public Health Service Act (42 U.S.C. 296 m) as amended by $\S 5404$ of the Patient Protection and Affordable Care Act (Pub. L. No. 111-148). Retrieved fromhttps://www.gpo.gov/fdsys/pkg/PLAW-111pub1148/pdf/PLAW-111publ148.pdf

[20] Joint Center for Political and Economic Studies. (2010, October). The Patient Protection and Affordable Care Act of 2010: Advancing health equity for racially and ethnically diverse populations. Retrieved from http://www.jointcenter.org/hpi/sites/all/files/PatientProtection_PREP_0.pdf

[21] Berwick, D., Nolan, T. \& and Whittington, J. (2008). The triple aim: Care, health, and cost. Health Affairs, 27(3), 759-769. doi: 10.1377/hlthaff.27.3.759 